\title{
Topochemical acetylation of cellulose nanopaper structures for biocomposites: mechanisms for reduced water vapour sorption
}

\author{
Ana Gisela Cunha • Qi Zhou • \\ Per Tomas Larsson • Lars A. Berglund
}

Received: 9 April 2014/Accepted: 12 June 2014/Published online: 25 June 2014

(C) The Author(s) 2014. This article is published with open access at Springerlink.com

\begin{abstract}
Moisture sorption decreases dimensional stability and mechanical properties of polymer matrix biocomposites based on plant fibers. Cellulose nanofiber reinforcement may offer advantages in this respect. Here, wood-based nanofibrillated cellulose (NFC) and bacterial cellulose (BC) nanopaper structures, with different specific surface area (SSA), ranging from 0.03 to $173.3 \mathrm{~m}^{2} / \mathrm{g}$, were topochemically acetylated and characterized by ATR-FTIR, XRD, solid-state CP/MAS ${ }^{13} \mathrm{C}$-NMR and moisture sorption studies. Polymer matrix nanocomposites based on NFC were also prepared as demonstrators. The surface degree of substitution (surface-DS) of the acetylated cellulose nanofibers is a key parameter, which increased with increasing SSA. Successful
\end{abstract}

Electronic supplementary material The online version of this article (doi:10.1007/s10570-014-0334-z) contains supplementary material, which is available to authorized users.

A. G. Cunha $(\bowtie) \cdot$ Q. Zhou · P. T. Larsson •

L. A. Berglund $(\bowtie)$

Wallenberg Wood Science Center, Royal Institute of

Technology (KTH), 10044 Stockholm, Sweden

e-mail: cunha@kth.se

L. A. Berglund

e-mail: blund@kth.se

\section{A. G. Cunha · L. A. Berglund}

Department of Fiber and Polymer Technology, Royal Institute of Technology (KTH), 10044 Stockholm,

Sweden topochemical acetylation was confirmed and significantly reduced the moisture sorption in nanopaper structures, especially at $\mathrm{RH}=53 \%$. BC nanopaper sorbed less moisture than the NFC counterpart, and mechanisms are discussed. Topochemical NFC nanopaper acetylation can be used to prepare moisturestable nanocellulose biocomposites.

Keywords Cellulose nanofibers - Bacterial cellulose - Nanopaper · Topochemical acetylation · Moisture sorption · Nanocomposites

\section{Introduction}

Cellulose is present in the form of nanoscale microfibrils in the plant cell wall, where it provides mechanical function to the whole plant structure (Niklas 1992). Recently, disintegration of cellulose

Q. Zhou

School of Biotechnology, AlbaNova University Center, Royal Institute of Technology (KTH), 10691 Stockholm, Sweden

P. T. Larsson INNVENTIA AB, P. O. Box 5604, 11486 Stockholm, Sweden 
to various forms of nanocellulose, and further modification and use in new materials has become an important research field (Klemm et al. 2011). Cellulose has good mechanical properties and many forms of cellulose fibers are used as reinforcement in composite materials (Belgacem and Gandini 2005; Berglund and Peijs 2010; Hubbe et al. 2008; Siqueira et al. 2010). The cellulosic plant fiber itself is present as a hydrated "gel" structure in the plant. The hemicellulose component, in particular, is highly hydrophilic. As relative humidity and temperature vary during the service of a plant fiber-based biocomposite, the fiber will swell and shrink as moisture diffuses in and out of the material. Hydrophobic polymer matrices cannot prevent this phenomenon (Abdelmouleh et al. 2005). The heterogeneous chemical composition of the plant fiber wall, and the presence of hemicelluloses and lignin, contributes to this problem. The main load-bearing function in the hydrated plant fiber cell wall is provided by the cellulose microfibrils due to the nature of the cellulose crystal and the extended chain conformation of cellulose molecules. The interior of the cellulose crystal itself is not accessible to water due to molecular close-packing (Sakurada et al. 1962). This is an important, and perhaps underestimated, argument in favor of nanocellulose reinforced biocomposites. High purity nanocellulose fibrils may show only limited moisture swelling and should have the potential to reduce moisture sensitivity of biocomposites based on plant fibers.

The fiber/matrix interface is critical for the microscale load transfer in biocomposites. Again, moistureinduced swelling and shrinkage will destroy the fiber/ matrix adhesion and reduce mechanical properties. Low strain to failure (brittleness) and moisture sensitivity was apparent in biocomposites based on bleached esparto grass pulp fibers and epoxy (Abdelmouleh et al. 2005). The moisture sensitivity was indeed interpreted as a loss of fiber/matrix interfacial adhesion.

The moisture sorption mechanisms of regenerated cellulosic fibers have been studied (Okubayashi et al. 2004). The early work on moisture sorption in cellulose is discussed in this study. For instance, Peirce introduced a model based on the assumption of both direct and indirect sorption of water molecules at reactive sites of the fibers (Peirce 1929). Later, Speakman presented a model that takes three types of water into account: primary- and secondary-bound, and bulk or free water (Speakman 1944). Two kinetic processes, defined as fast and slow, have been identified. The processes correspond to slow and fast sorption sites, comprising amorphous regions, external/internal fiber surfaces and direct/indirect sorption (Morton and Hearle 1997).

Despite the extensive literature on the topic of cellulose-water interactions, the mechanisms behind such interactions at different relative humidity $(\mathrm{RH})$ are not completely clear. One reason is in the complex supramolecular structure of cellulosic fibers. Mihrayan et al. (2004) demonstrated the importance of specific surface area and degree of crystallinity. Stone and Scallan (1968) addressed the complex structure of bleached cellulose wood pulp, including the scale of individual cellulose microfibrils. Nanocellulose fibrils or porous nanopaper are of interest in this context, since the structure may be simpler compared with a pulp fiber. A cellulose nanofiber can in favorable cases be viewed as a purified component of a plant fiber or chemical pulp fiber.

A promising approach to cellulose modification is topochemical modification, in which the reactions are limited to the groups present in the accessible regions of nanoscale entities (Belgacem and Gandini 2005). This is in contrast to homogeneous conditions, where the modification occurs in the bulk of the fibers, usually through a dissolution approach. Acetylation was one of the first chemical reactions used for cellulose fibers and is still important (Klemm et al. 1998). Sassi and Chanzy (1995) demonstrated the true topochemical character of Valonia and Tunicate whisker acetylation and explained ultrastructure effects. Kim et al. (2002) showed that the crystallinity of bacterial cellulose submitted to acetylation treatment can be preserved for increasing bulk degrees of acetylation up to a maximum of 0.37 . Despite the frequent use of acetylation, the mechanisms for how acetylation influences properties of the final cellulosebased products are not well understood. This is particularly true when controlled heterogeneous conditions are applied. In particular, the effect of acetylation on moisture sorption of nanocellulose is not well understood.

Rowell and Rowell (1989) claimed that the direct acetylation of wood fibers is the most efficient way to reduce their equilibrium moisture content. They suggested that lignin and hemicelluloses were 
acetylated, whereas cellulose acetylation did not occur. Possibly, acetylation of cellulose is very limited when large amounts of lignin and hemicellulose are present.

A previous study by Ifuku et al. (2007) on bacterial cellulose (BC)/acrylic resin composites demonstrated that increasing degree of $\mathrm{BC}$ acetylation decreased composites moisture sorption at $\mathrm{RH}=55 \%$. However, for high degrees of substitution (DS) $>0.56$ the moisture sorption started to increase. This was attributed to a partial disruption of the crystalline domains in the fibrils, as assessed from X-ray diffraction (XRD) results. Crystallinity is an important parameter in evaluation of the topochemical nature of chemical modifications.

Likewise, acetylated cellulose nanofibrils, from both wood (Tingaut et al. 2010) and bacterial origin (Tomé et al. 2011), were used as reinforcing agent in poly(lactic acid) (PLA) biocomposites. The increased moisture sorption (Tingaut et al. 2010)/water uptake (Tomé et al. 2011) of the biocomposites compared with neat PLA was attributed to the cellulosic nanofibrils added, since sorption scaled with cellulose content. Nevertheless, the moisture sorption/water uptake was lower for the biocomposites with acetylated fibrils compared to those with unmodified cellulose nanofibrils. Tingaut et al. (2010) also demonstrated that increased acetyl content in the cellulose correlated with reduced moisture sorption.

Previous studies tend to focus on the moisture sorption of composites containing acetylated cellulose fibrils, and not on the sorption of the acetylated fibrils per se. Nonetheless, some studies have addressed this topic (Boissard et al. 2011; Rampinelli et al. 2010), although not with respect to detailed mechanisms. For instance, Rampinelli et al. (2010) verified that acetylated microfibrillated cellulose, extracted from bamboo, sorbed less moisture than the unmodified counterparts. This was credited to partial substitution of the hydrophilic $\mathrm{OH}$ groups in cellulose. However, this was accompanied by weakening of hot-pressed MFC films, possibly due to reduced interfibril adhesion. In the present study, acetylation was therefore performed after preparation of nanopaper structures.

For the purpose of PLA foam reinforcement, Boissard et al. (2011) tested the moisture sorption in pre-modified powdered cellulose nanofibrils, including acetylated samples with three different DS. They verified a progressive reduction in moisture uptake as function of increasing DS.
The present work is different from previous studies in its objective to further the understanding of nanocellulose structure, acetylation efficiency and its potential to address the moisture sorption problem in wood nanocellulose materials. Moisture sorption is studied in cellulose nanofibrils per se organized in nanopaper structures of known specific surface area, degree of crystallinity and estimated degree of acetylation at the nanocellulose surface. Wood-based nanofibrillated cellulose (NFC) was studied due to its potential application in new materials, whereas bacterial cellulose was viewed as a model material and analyzed for comparative purposes. The NFC and BC nanofibrils were acetylated under a set of mild conditions, and the properties of the ensuing products, with special focus on their moisture sorption capacity at different $\mathrm{RH}$, were studied and compared.

\section{Experimental}

\section{Materials}

Nanofibrillated cellulose (NFC) was prepared from softwood sulphite pulp fibers (DP of 1200, lignin and hemicelluloses content of 0.7 and $13.8 \%$, respectively, Nordic Pulp and Paper, Sweden) according to a method previously described (Henriksson et al. 2007).

Bacterial cellulose (BC) was produced by the bacterial strain Acetobacter aceti (AJ-12368), a cellulose producing species closely related to G. xylinus, in the Schramm-Hestrin ( $\mathrm{SH}$ ) medium (Hestrin and Schramm 1954). An aqueous suspension of BC nanofibrils was obtained by homogenizing the $\mathrm{BC}$ pellicles with a OBH Nordica blender.

All the reagents and solvents were supplied either by Sigma-Aldrich or Fisher Scientific and used as received.

Preparation of the cellulose nanopapers

NFC and BC aqueous suspensions with concentration of $0.15 \mathrm{wt} \%$ were prepared by dilution of the original suspensions, mixed at 12,000 rpm using an Ultra Turrax mixer (IKA, D125 Basic) for $10 \mathrm{~min}$ and, subsequently, degassed under vacuum. Films $(\varnothing=72 \mathrm{~mm})$ of these two cellulosic substrates were prepared by vacuum filtration of the aqueous suspensions on a glass filter funnel, using a $0.65 \mu \mathrm{m}$ pore size filter membrane 
Table 1 Identification of the samples prepared according to the experimental conditions

\begin{tabular}{lll}
\hline Sample & Precursor & $\begin{array}{l}\text { Reaction } \\
\text { temperature }\left({ }^{\circ} \mathrm{C}\right)\end{array}$ \\
\hline NFCcpd-Ac1 & NFCcpd-Ref & RT \\
NFCcpd-Ac2 & & 50 \\
NFCfd-Ac1 & NFCfd-Ref & RT \\
NFCfd-Ac2 & & 50 \\
NFCd-Ac1 & NFCd-Ref & RT \\
NFCd-Ac2 & & 50 \\
BCcpd-Ac1 & BCcpd-Ref & RT \\
BCfd-Ac1 & BCfd-Ref & RT
\end{tabular}

(DVPP, Durapore ${ }^{\circledR}$, Millipore). Subsequently, in order to obtain nanopapers with tailored specific surface area (SSA), the wet films were dried either by supercritical point drying in a Tousimis Autosamdri-815 critical point drier (CPD) or by freeze-drying in a Scanvac CoolSafe freeze-drier (FD). In the case of NFC, the wet films were also dried at $93{ }^{\circ} \mathrm{C}$ under vacuum in a semiautomatic sheet former Rapid-Köthen (RK). Before being dried in the CPD, the wet films were solvent exchanged, first to methanol $70 \%$ and then to pure methanol, for $24 \mathrm{~h}$.

In this study, NFC- and BC-control samples are differentiated according to the technique used to dry them. Hence, samples dried by CPD are referred as cpd-Ref, samples dried by FD as fd-Ref and those dried by RK simply as d-Ref.

\section{Acetylation of cellulose nanopaper}

Cellulose nanopapers $(\sim 300 \mathrm{mg})$ with different specific surface area (SSA) were immersed in anhydrous toluene and one equivalent (relative to the total $\mathrm{OH}$ groups of cellulose) of acetic anhydride was added under stirring. Subsequently, a catalytic amount of sulphuric acid $96 \%(2 \mu \mathrm{L})$ was dropped into the mixture and the reaction was conducted either at room temperature (RT, $\sim 21{ }^{\circ} \mathrm{C}$ ) or $50{ }^{\circ} \mathrm{C}$ for $30 \mathrm{~min}$ (only for the NFC samples). At the end of the reaction, the acetylated nanopaper was sequentially washed with acetone, ethanol, distilled water, and again with ethanol and dried by means of the same drying technique used previously in their preparation.

The samples thus prepared are listed in Table 1, in which samples treated at RT are denoted as Acl and samples treated at $50{ }^{\circ} \mathrm{C}$ as $A c 2$.
Moisture sorption measurements

Small pieces of control and acetylated nanopaper ( $\sim 10 \mathrm{mg}$ ) were kept in hermetic boxes containing different RH, specifically 53, 84 and $100 \%$, until the adsorption equilibrium was reached and their weight stabilized, or directly immersed in distilled water for the same period of time. The nanocomposites prepared (Supporting information, Section S3) were kept only at $\mathrm{RH}=84 \%$. Once reached the adsorption equilibrium, the percentage of moisture sorption/water uptake $\left(W_{\text {sorption }}\right)$ was calculated according to:

$W_{\text {sorption }}=\left(\frac{W_{f}-W_{o}}{W_{o}}\right) \times 100$

where $W_{O}$ stands for the initial weight of the sample and $W_{f}$ for its weight after the adsorption equilibrium was reached.

The measurements were performed twice for each sample.

\section{Characterization}

Specific surface area (SSA) was estimated by $\mathrm{N}_{2}$ physisorption using a Micromeritics ASAP 2020 automated system according to Brunauer-EmmettTeller (BET) theory (Brunauer et al. 1938). Prior to the analysis, samples were degassed in the Micromeritics ASAP 2020 at $115^{\circ} \mathrm{C}$ for $4 \mathrm{~h}$, and subsequently submitted to $\mathrm{N}_{2}$ adsorption at $-196{ }^{\circ} \mathrm{C}$. BET analysis was carried out for a relative vapor pressure of $0.01-0.3$ at $-196{ }^{\circ} \mathrm{C}$. For the control CPD-dried samples, NFCcpd-Ref and BCcpd-Ref, SSA was also estimated from the ${ }^{13} \mathrm{C}$-NMR data as described in the supporting information (Section S1i).

The porosity of the nanopapers was indirectly estimated according to the mercury displacement method using an Archimedes scale (Baggerund et al. 2003). The density was calculated from the displacement for the sample when immersed in mercury (Baggerund et al. 2003). Porosity was then calculated from the measured density according to Eq. 2,

Porosity $=\left(1-\frac{\rho_{f}}{\rho_{c}}\right) \times 100$

where $\rho_{f}$ corresponds to the density of the nanopaper and $\rho_{c}$ corresponds to the density of cellulose, which was assumed to be $1,460 \mathrm{~kg} / \mathrm{m}^{3}$ (Sun 2008). The 
calculated porosities are estimates, which depend on accuracy of density assumption. The purpose is simply to facilitate comparison between different materials.

Field emission scanning electron microscopy (FESEM) was conducted in a Hitachi S-4800 scanning electron microscope operating at $3 \mathrm{kV}$. The dry samples were fixed on metal stubs using carbon tape and coated with a thin layer of gold/palladium alloy (ca. $3 \mathrm{~nm}$ ) using a Cressington 208HR sputter coater.

Fourier-transform infrared (FTIR) spectra were recorded using a Perkin-Elmer Spectrum 2000 FTIR equipped with a Specac MKII Golden Gate, single reflection attenuated total reflectance (ATR) system. The acquisition conditions were 8 scans and $4 \mathrm{~cm}^{-1}$ resolution. The spectra were normalized against the band centered at ca. $1,030 \mathrm{~cm}^{-1}$ attributed to $\mathrm{C}-\mathrm{O}$ stretching.

Cross-polarization/magic angle spinning ${ }^{13} \mathrm{C}$ nuclear magnetic resonance (CP/MAS ${ }^{13} \mathrm{C}-\mathrm{NMR}$ ) spectra were recorded using a Bruker Avance III AQS 400 SB instrument operating at 9.4 T. Prior to the measurements the dried samples were packed uniformly in a zirconium oxide rotor. All measurements were performed at $295 \pm 1 \mathrm{~K}$ with a MAS rate of $10 \mathrm{kHz}$. A $4 \mathrm{~mm}$ double air-bearing probe was used. Acquisition was performed using a $\mathrm{CP}$ pulse sequence, i.e., a $2.95 \mu$ s proton $90^{\circ}$ pulse and a $800 \mu$ s ramped (100-50\%) falling contact pulse, with a $2.5 \mathrm{~s}$ delay between repetitions. A SPINAL64 pulse sequence was used for ${ }^{1} \mathrm{H}$ decoupling. The Hartmann-Hahn matching procedure is based on glycine. The chemical shift scale was calibrated to the TMS $\left(\left(\mathrm{CH}_{3}\right)_{4} \mathrm{Si}\right)$ scale by assigning the data point of maximum intensity in the $\alpha$-glycine carbonyl signal to a shift of $176.03 \mathrm{ppm}$. A total of 4,096 transients were recorded on each sample, giving an acquisition time of approximately $3 \mathrm{~h}$. The software for spectral fitting was developed at Innventia $\mathrm{AB}$ and is based on a Levenberg-Marquardt algorithm (Larsson et al. 1997).

X-ray diffraction (XRD) patterns were measured in a Philips X'Pert Pro diffractometer (model PW 3040/60) using $\mathrm{Cu} \mathrm{K} \alpha$ radiation. Diffractograms were recorded in the reflection mode in a $2 \theta$ angular range $5-40^{\circ}$, by steps of $0.05^{\circ}$, from rotating specimens (revolution time $8 \mathrm{~s}$ ) using position sensitive detector (X'Celerator detector). The two peaks centered at about $14.8^{\circ}$ and $16.8^{\circ}$ in the $\mathrm{X}$-ray diffraction patterns correspond to d-spacings of $0.60-0.61$ and $0.53-0.54 \mathrm{~nm}$, respectively. These two peaks were separated by curve fitting using the pseudoVoigt function. The crystal sizes of the corresponding
Table 2 BET specific surface area (SSA) and porosity of unmodified nanocellulose films

\begin{tabular}{llll}
\hline Sample & $\begin{array}{l}\text { Drying } \\
\text { technique }\end{array}$ & $\begin{array}{l}\text { BET SSA } \\
\left(\mathrm{m}^{2} / \mathrm{g}\right)\end{array}$ & $\begin{array}{l}\text { Porosity } \\
(\%)\end{array}$ \\
\hline NFCcpd-Ref & CPD & $173.3 \pm 6.3$ & $86.2 \pm 2.6$ \\
BCcpd-Ref & & $98.0 \pm 3.5$ & $86.8 \pm 3.1$ \\
NFCfd-Ref & FD & $43.4 \pm 2.1$ & $71.9 \pm 0.1$ \\
BCfd-Ref & & $34.6 \pm 1.3$ & $72.4 \pm 0.9$ \\
NFCd-Ref & RK & $0.03 \pm 0.01$ & $36.2 \pm 2.7$ \\
\hline
\end{tabular}

planes were calculated from full widths at half heights of the diffraction peaks by Scherrer's equation. The crystallinity index (CrI) was determined from the ratio of the separated crystalline peak area to the total reflection area including background (Pei et al. 2013; Salajkova et al. 2012).

\section{Results and discussion}

\section{Characterization of cellulose nanopaper}

The specific surface area (SSA) and porosity of the unmodified cellulose nanopaper structures are listed in Table 2.

Samples dried by supercritical drying (CPD), present the highest SSA values, 173.3 and $98.0 \mathrm{~m}^{2} / \mathrm{g}$, for NFcpd-Ref and BCcpd-Ref, respectively. CPD is very efficient to dry samples and avoiding collapse due to surface tension effects (also referred as capillary effects) during water evaporation (Sehaqui et al. 2011). Whereas water has high surface tension to air $\left(72.9 \mathrm{mN} / \mathrm{m}\right.$ at $\left.20^{\circ} \mathrm{C}\right)$, the samples were solventexchanged first to methanol $\left(22.5 \mathrm{mN} / \mathrm{m}\right.$ at $\left.20^{\circ} \mathrm{C}\right)$, and then to liquid $\mathrm{CO}_{2}\left(1.7 \mathrm{mN} / \mathrm{m}\right.$ at $\left.22{ }^{\circ} \mathrm{C}\right)$, before supercritical drying (Adamson and Gast 1997).

Samples dried by freeze-drying (FD) and from liquid water (RK) possess much lower SSA values than the CPD-dried counterparts, around 40 and $0 \mathrm{~m}^{2} /$ $\mathrm{g}$, respectively. These samples were dried from water, and suffered capillary effects that led to "co-crystallization" or hornification of cellulose crystallites (Newman 2004). The FD technique results in higher SSA, since samples are dried by sublimation of the ice crystals (Sehaqui et al. 2011), rather than from liquid water. Wood NFC nanopaper possessed higher SSA than the bacterial cellulose (BC) analogues, due to the larger lateral dimension of $\mathrm{BC}$ ribbons. 

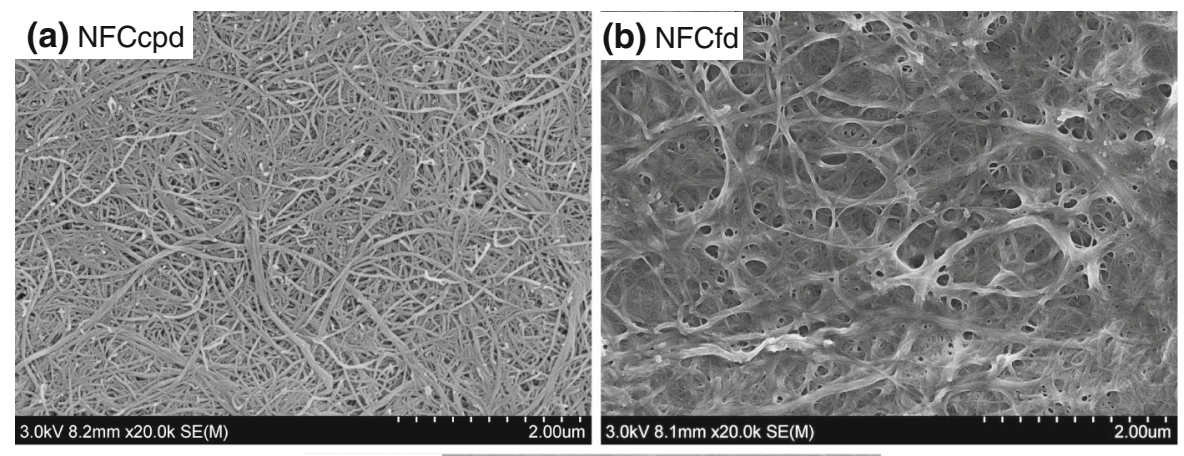

(c) NFCd

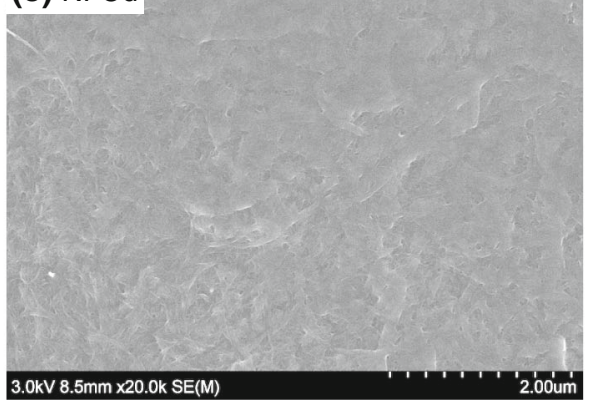

Fig. 1 Morphology of the a CPD-dried, b FD-dried and $\mathbf{c}$ RK-dried control NFC nanopapers as assessed by FE-SEM. Scale bar in all images is $2 \mu \mathrm{m}$

SSA of control NFC and BC CPD-dried nanopaper was also estimated based on the respective solid-state $\mathrm{CP} / \mathrm{MAS}{ }^{13} \mathrm{C}$ NMR spectra (Supporting information, Section S1i). Accordingly, the values obtained were $152 \pm 9$ and $98 \pm 6 \mathrm{~m}^{2} / \mathrm{g}$, for NFCcpd-Ref and BCcpd-Ref, respectively, which connect well to data attained by BET measurements (Table 2).

The porosity of the unmodified nanopaper correlated with SSA results so that samples with higher SSA presented higher porosity. The porosity ranged from 35 to $90 \%$ (Table S1), and CPD-dried nanopaper is more porous than FD-dried counterparts, and RKdried samples have the lowest porosity.

The surface morphology of the control nanopaper was examined by field emission scanning electron microscopy (FE-SEM). In agreement with the SSA and porosity data, high SSA nanopapers (dried in CPD) displayed significant porosity (Fig. 1a), while the low SSA analogues (dried in RK) revealed a very compact and more agglomerated structure (Fig. 1c). The FD-dried samples displayed an intermediate state of agglomerated structure (Fig. 1b). The pore size, as estimated by visual evaluation of the FE-SEM micrographs (Fig. 1), was heterogeneous and ranged between 10 and $100 \mathrm{~nm}$. For the RK-dried samples, the pore size could not be evaluated by this method because the pores are too small.

Topochemical acetylation of cellulose nanopaper

NFC nanopaper samples were acetylated using two different reaction temperatures, viz., $\mathrm{RT}\left(\sim 21{ }^{\circ} \mathrm{C}\right)$ and $50{ }^{\circ} \mathrm{C}$. The $\mathrm{BC}$ nanopaper was used for comparative purposes and modified only at RT. The confirmation of successful acetylation was assessed by ATR-FTIR spectroscopy (Fig. 2), through the monitoring of new bands at $\sim 1,730,1,370$ and $1,210 \mathrm{~cm}^{-1}$, assigned to the $\mathrm{C}=\mathrm{O}$ stretching mode, $\mathrm{C}-\mathrm{H}$ symmetrical deformation in $\mathrm{CH}_{3}$ and $\mathrm{C}-\mathrm{O}$ stretching vibration of the acetate groups (Bellamy 1975). Moreover, the decreased intensity of the band related to the $\mathrm{O}-\mathrm{H}$ stretching at $3,340 \mathrm{~cm}^{-1}$ gave further evidence of successful acetylation (Bellamy 1975).

The extent of acetylation increased as the reaction temperature was increased from RT to $50{ }^{\circ} \mathrm{C}$ (Fig. 2a). Note the appearance of new peaks characteristic for acetylation in the two upper curves. In Fig. 2b, peaks associated with $\mathrm{C}=\mathrm{O}, \mathrm{C}-\mathrm{H}$ and $\mathrm{C}-\mathrm{O}$ are strongest and the degree of acetylation is highest for the sample with the highest SSA (cpd-Ac2). Samples with lower SSA 


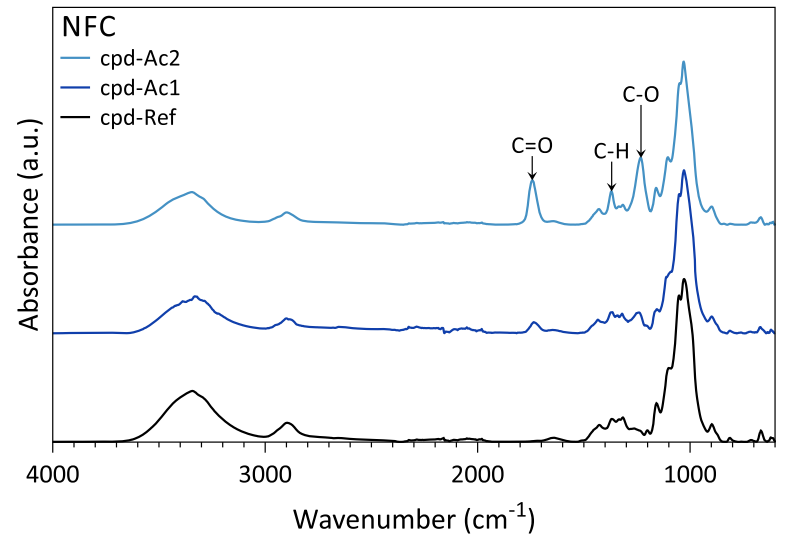

Fig. 2 ATR-FTIR spectra of a NFC CPD-dried samples, control (cpd-Ref) and acetylated (cpd-Ac1, cpd-Ac2) samples and b NFC samples acetylated at $50{ }^{\circ} \mathrm{C}$ (Ac2) and dried by

(fd-Ac2 and d-Ac2) showed weaker peaks and lower degree of acetylation.

$\mathrm{BC}$ nanopaper showed higher extent of acetylation compared to the NFC counterparts (Fig. 3). The reason for this is unclear, although one may note that the cellulose purity is much higher in BC. If some hemicelluloses are acetylated in NFC, they may be removed during rinsing so that cellulose acetylation is less efficient than in BC.

The effects from acetylation was also assessed by FE-SEM. The morphology of the modified nanopaper remained similar to that of control samples, as exemplified in Fig. 4 for control and acetylated $\left(50{ }^{\circ} \mathrm{C}\right) \mathrm{CPD}$-dried NFC nanopaper. If the acetylation had resulted in significant derivatization, a morphology similar to Fig. 4c would be expected. The thickness of the nanofibrils would increase so that a film-like structure would be apparent.

Solid-state CP/MAS ${ }^{13} \mathrm{C}$ NMR results gave further evidence of the success of topochemical acetylation. As exemplified for NFC (cpd-Ac2), new resonances emerged in the spectra of the modified NFC (Fig. 5), which were attributed to the new aliphatic $(\sim 20 \mathrm{ppm})$ and carboxylic carbons $(\sim 165 \mathrm{ppm})$ of the acetate groups. In accordance with the ATR-FTIR results, these resonances were more prominent for the samples modified at the highest temperature $\left(50{ }^{\circ} \mathrm{C}\right)$, especially in the case of the high SSA sample (NFCcpdAc2).

The integration of the signal related to the new methyl group was used to estimate the bulk degree

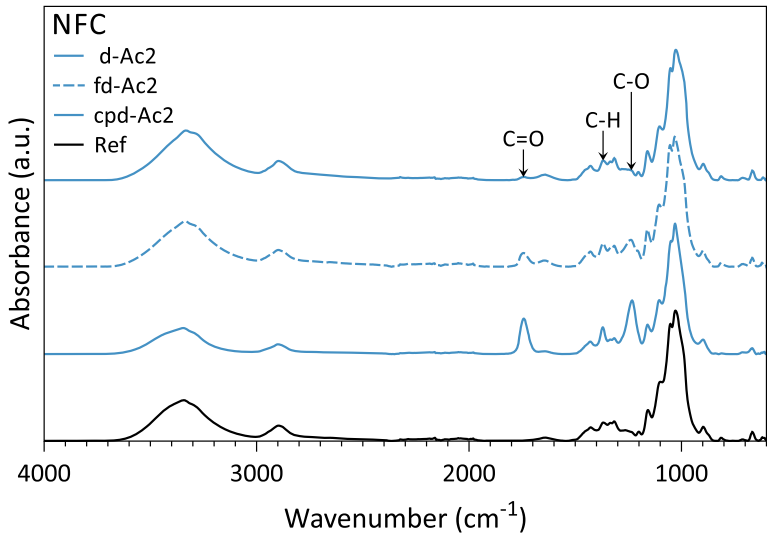

different techniques (critical point drying: cpd-Ac2, freeze drying: fd-Ac2, Rapid Köthen: d-Ac2) so that the SSA varied

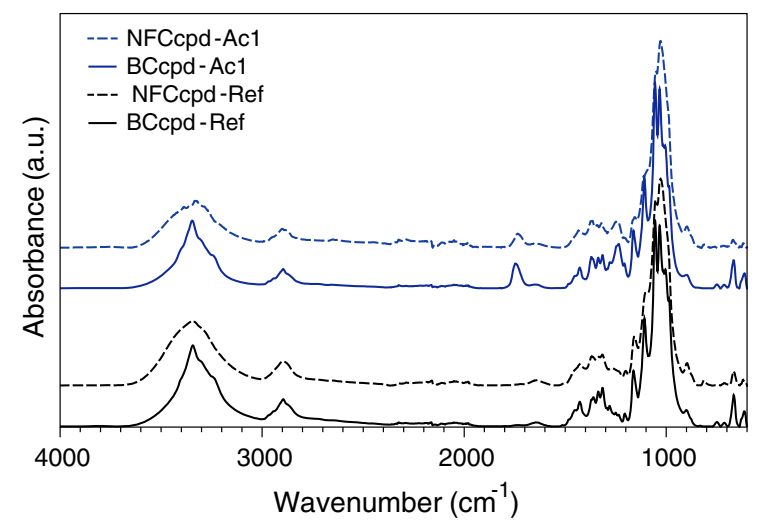

Fig. 3 ATR-FTIR spectra of CPD-dried nanopaper with high SSA, based on NFC and BC. The two lower spectra are from reference samples before acetylation (BCcpd-Ref, NFCcpdRef). The two upper spectra are from samples subjected to the same acetylation conditions (BCcpd-Ac1, NFCcpd-Ac1). Note the strength of new peaks associated with acetylation $(1,730$, $1,370,1,210 \mathrm{~cm}^{-1}$ )

of substitution (bulk-DS) (Supporting information, Section S1i) (Table 3). This represents the DS if all three hydroxyls per anhydroglucose unit (AGU) of all molecules were accessible. The bulk-DS is obviously not representative of the DS at the NFC and BC surface (surface-DS). A first hypothesis is that only the hydroxyls at the fibril surface and those in the less ordered regions are accessible. At low degrees of substitution the average surface-DS can be estimated from the surface-to-bulk $\mathrm{OH}$ ratio. This ratio was calculated from the SSA data and basic assumptions (Supporting information, Section S1iii). 

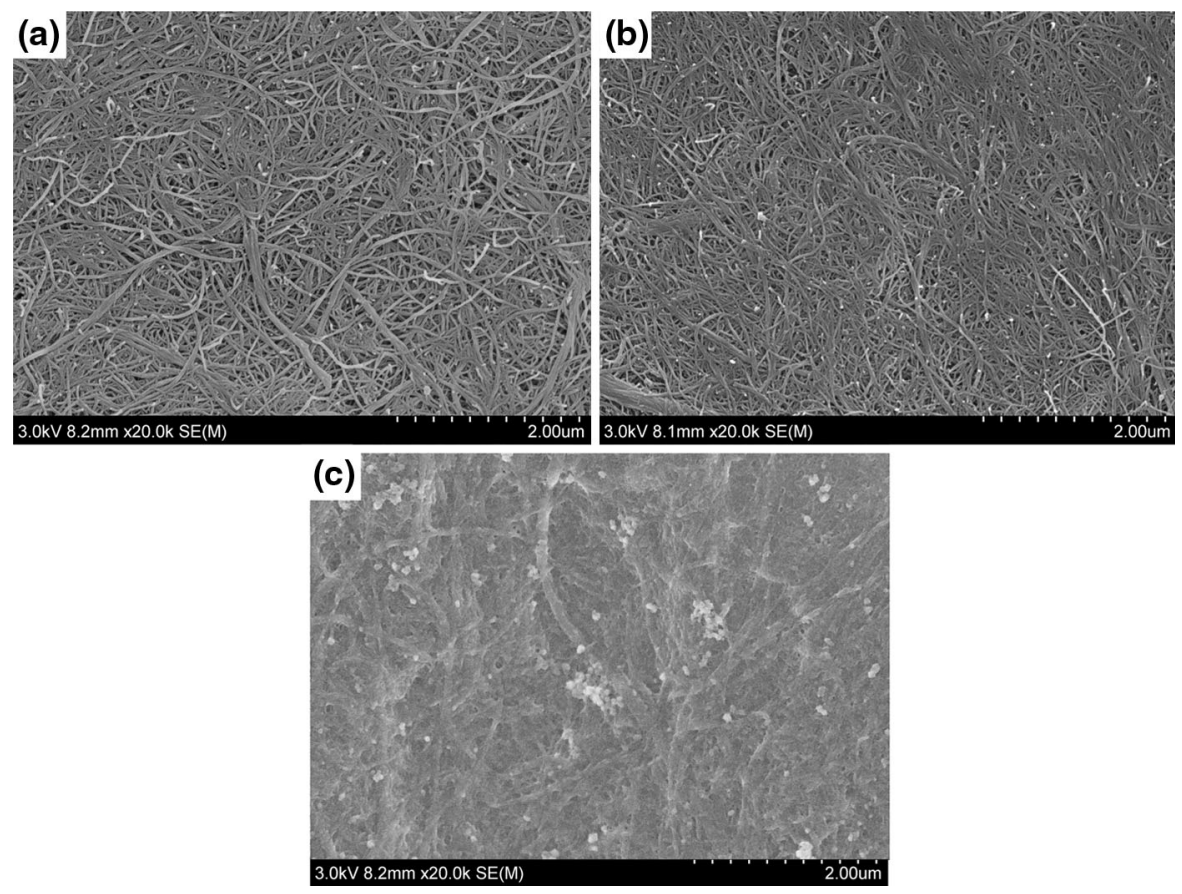

Fig. 4 FE-SEM surface micrographs of a NFCcpd-Ref, b NFCcpd-Ac2 and c over-acetylated NFCcpd nanopapers

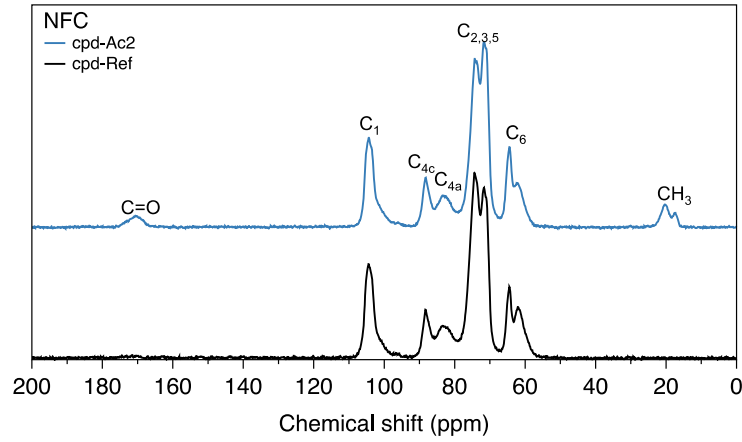

Fig. 5 Solid-state ${ }^{13} \mathrm{C}$ NMR spectra of unmodified (cpd-Ref) and acetylated $\left(50{ }^{\circ} \mathrm{C}\right)$ (cpd-Ac2) NFC samples dried by critical point drying to an SSA of $173 \mathrm{~m}^{2} / \mathrm{g}$

Subsequently, the surface-DS was estimated by division of the bulk-DS by the surface-to-bulk $\mathrm{OH}$ ratio (Supporting information, Equation S4).

As displayed in Table 3, a wide range of surfaceDS was obtained, from 0.2 up to 1.9. Theoretically, a value of 1.5 is the maximum surface-DS if only the surface of crystalline regions is considered. Values higher than 1.5 indicate that disordered non-surface regions have also been acetylated. At the other extreme, the bulk-DS of the low SSA samples (dried
Table 3 Bulk degree of substitution (bulk-DS) and surface degree of substitution (surface-DS) of acetylated nanopapers

\begin{tabular}{llll}
\hline $\begin{array}{l}\text { Reaction } \\
\text { temperature }\end{array}$ & & Bulk-DS & Surface-DS \\
\hline RT & NFCcpd-Ac1 & $0.028 \pm 0.004$ & 0.2 \\
& NFCfd-Ac1 & $0.014 \pm 0.001$ & 0.4 \\
& NFCd-Ac1 & n.d. $^{\mathrm{a}}$ & n.a. \\
& BCcpd-Ac1 & $0.115 \pm 0.004$ & 1.4 \\
& BCfd-Ac1 & $0.037 \pm 0.001$ & 1.3 \\
$50{ }^{\circ} \mathrm{C}$ & NFCcpd-Ac2 & $0.282 \pm 0.004$ & 1.9 \\
& NFCfd-Ac2 & $0.045 \pm 0.002$ & 1.2 \\
& NFCd-Ac2 & n.d. ${ }^{\mathrm{a}}$ & n.a.
\end{tabular}

\footnotetext{
${ }^{a}$ Not detectable

b Not available
}

from water in Rapid Köthen) was not possible to retrieve, due to the detection limit of the technique. Low degree of acetylation is confirmed by the low intensity of the new bands in the corresponding ATRFTIR spectra (Fig. 2) (bulk-DS < 0.01).

The importance of SSA is also apparent in NMR acetylation data for high SSA CPD-dried samples, since those samples showed the highest bulk-DS 
values ( 0.282 and 0.115 , for NFCcpd-Ac2 and BCcpdAc1 in Table 3), in agreement with ATR-FTIR results.

$\mathrm{BC}$ samples presented higher surface-DS than the NFC counterparts (comparing samples treated under the same conditions). The reason is unclear but one may note that $\mathrm{BC}$ is pure cellulose. It is possible that impurities in NFC (i.e., hemicellulose residues) are acetylated and then removed during rinsing, and therefore not detected in NMR experiments.

\section{Supramolecular structure}

In a previous study, moisture sorption of acetylated cellulose was high for specimens with high bulk-DS (Ifuku et al. 2007). High bulk-DS may cause extensive derivatization and degradation of fibril structure. In order to confirm preserved fibrils, the supramolecular structure was characterized by solid-state ${ }^{13} \mathrm{C}$ NMR and XRD. For NMR, the degree of crystallinity results from evaluation of the $\mathrm{C}_{4}$ signal of cellulose (Fig. 5). The signal cluster is split into a sharp signal at 86-91 ppm (associated with the ordered regions, $\mathrm{C}_{4 \mathrm{c}}$ ) and a broader signal at 80-86 pm (associated with less ordered regions, $\mathrm{C}_{4 \mathrm{a}}$ ) (Larsson et al. 1997). The intensity of the crystalline signals was similar to control nanocelluloses for all acetylated samples (Fig. 5). Apparently, acetylation did not affect the ordered regions, in support of successful topochemical modification.

Samples were also analyzed by XRD. As exemplified in Fig. 6a for the high SSA NFC samples, the acetylated nanopaper presented diffractograms similar to the controls, in support of preserved crystallites. Typical XRD pattern of cellulose I was observed, with the diffraction signals at $2 \theta$ values of $14.9,16.3,22.5$ and $34.6^{\circ}$, assigned to the $1 \overline{1} 0,110,200$ and 004 diffraction planes, respectively (Wada et al. 1993, 1997).

On the whole, both the crystallinity index CrI and crystallite dimensions were preserved after acetylation (Supporting information, Table S1), in agreement with solid-state ${ }^{13} \mathrm{C}$-NMR results. Acetylation is expected in the most available regions, viz., disordered domains and crystallite surfaces (Belgacem and Gandini 2008; Ciolacu et al. 2011). Crystallite parameters varied slightly with SSA (Supporting information, Table S1). Specifically, CrI ranged from 55 to $65 \%$ and from 70 to $76 \%$, in the case of NFC and $\mathrm{BC}$, respectively. Previous studies have shown that different drying methods can lead to slight changes in crystallinity (Chuniall et al. 2010; Zhang et al. 2011). For instance, the rate at which water is removed from cellulose fibers leads to changes in the lateral fibril aggregate dimensions (Chuniall et al. 2010). BC samples showed slightly higher CrI than the NFC counterparts, in agreement with the literature (Klemm et al. 2011). This is supported by observation of the corresponding diffractograms (Fig. 6b), which display sharper and better-resolved diffraction peaks for the BC. It is apparent that the term "successful acetylation" requires a definition in terms of DS, although bulkDS is not a suitable parameter for the case of topochemical modification. Instead, an accurate method for surface-DS is desirable.

\section{Moisture sorption}

The moisture sorption of cellulose is related to the accessible areas of the fibrous structure such as noncrystalline domains and crystallite surfaces (Gehlen 2010; Hermans 1946; Howsmon 1949; Okubayashi et al. 2004). As a consequence, the sorbed moisture content is a function of the supramolecular structure of the cellulose system (Froix and Nelson 1975). The cellulose source and the processing method will influence the result (Froix and Nelson 1975; Hermans 1946). Cellulose-water interactions depend on the stoichiometry of water molecules per AGU, the primary location of binding, so that three states of water, viz., tightly bound, intermediately bound and bulk water, are obtained (Froix and Nelson 1975). Acetate groups changes the surface tension of cellulose, and moisture diffusion will be influenced (Bochek and Kalyuzhnaya 2002).

In Fig. 7a, the moisture content of unmodified NFC increases with increased SSA. This correlation is in support of moisture adsorption due to surface hydration (especially for $\mathrm{RH}<53 \%$ ). Nonetheless, the moisture content at steady-state in all the unmodified NFC and BC samples (Table 4) was lower than that in natural plant and wood fibers (at similar relative humidities) reported in pioneering studies on water uptake by cellulosic materials (Howsmon 1949; Klemm et al. 1998; Philipp 1952). Next, data for acetylated NFC are presented. For a given SSA, the moisture content at steady state decreases substantially with increasing surface-DS (Fig. 7b, c and d). From Fig. $7 d$ it is also clear that acetylation affected 
(a)

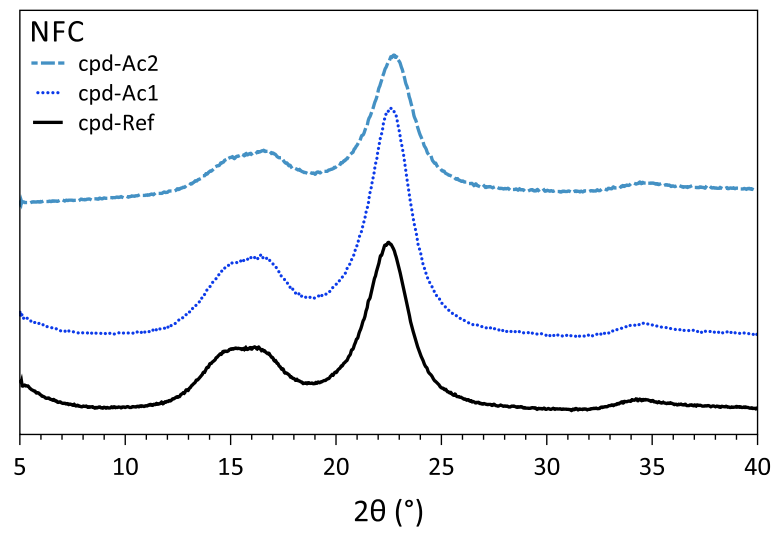

(b)

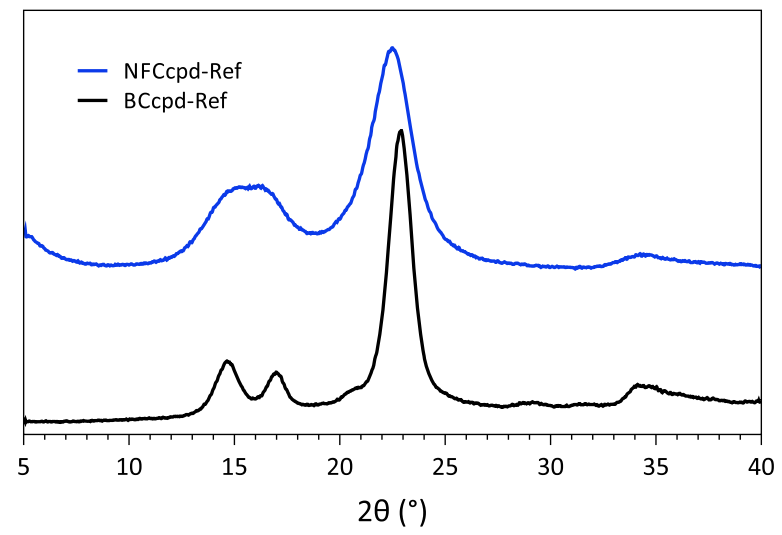

Fig. 6 X-ray diffractograms of a control and acetylated CPD-dried NFC nanopapers and $\mathbf{b}$ control CPD-dried NFC and BC nanopapers

the kinetics of moisture sorption. Samples with higher DS not only sorbed significantly less moisture, but adsorption steady state was also attained faster, as observed previously (Boissard et al. 2011; Tingaut et al. 2010; Tomé et al. 2011).

From Fig. 7e and $\mathrm{f}$ it is apparent that BC and NFC of roughly comparable SSA behave very differently. BC sorbed much less moisture then wood-based NFC possibly due to the higher degree of crystalline order. It is noteworthy that the moisture content in the acetylated samples is just $40 \%$ (NFC) or $20 \%$ (BC) of that in the precursor samples (Table 4 and Supporting information, Table S2).

In Fig. 8, the relative change in moisture content with surface-DS is presented for two NFC samples with different SSA. The effect of surface-DS was somewhat stronger at the lowest RH, i.e., RH $=53 \%$, see the slopes in the graph.

Regarding uptake of liquid water, the trend was the same as for moisture sorption data. Even for the high SSA CPD-dried samples (NFCcpd-Ac2) only $60 \%$ was adsorbed compared with the unmodified reference (Table 4 and Supporting information, Tables S2). Moreover, acetylation was more effective in preventing water-uptake rather than vapor sorption at $\mathrm{RH}=100 \%$ (Table 4 and Supporting information, Tables S2). This is probably related to steric hindrance provided by the new acetate groups, which was more efficient against water clusters in liquid state, whereas individual water vapor molecules can diffuse more easily and reach hydroxyl groups in acetylated samples (Peydecastaing et al. 2011).

Nanocellulose-based materials with low moisture sorption

Demonstration 1 Two NFC nanopapers with the highest DS were hot-pressed under vacuum after acetylation, one immediately after washing (wet-state, NFCcpd-Ac2-wp) and the other after a CPD-drying step (dry-state, NFCcpd-Ac2-p). These samples were then kept at the different $\mathrm{RH}$ and the moisture sorption capacity was evaluated and compared to that of the precursor acetylated NFC sample (NFCcpd-Ac2).

The hot-pressing resulted in samples with lower SSA and porosity than their precursors (Supporting information, Table S3), especially when compressed in the wet-state. As exemplified in Fig. 9, hot-pressing reduced the moisture content significantly for the nanocellulose samples. The NFCcpd-Ac2-wp sample showed no moisture sorption at $\mathrm{RH}=53 \%$. This indicates the potential of combined acetylation and hot-pressing for reduced moisture content in cellulosebased materials.

This hot-pressing was slightly more effective to prevent sorption of liquid water compared with vaporphase water $(\mathrm{RH}=100 \%)$. The NFCcpd-Ac2-wp sample, adsorbed only $35 \%$ of the water sorbed by the precursor sample (Supporting information, Tables S4 and S5). The reason is lowered SSA and porosity due to the thermo-mechanical hot-pressing treatment. This 

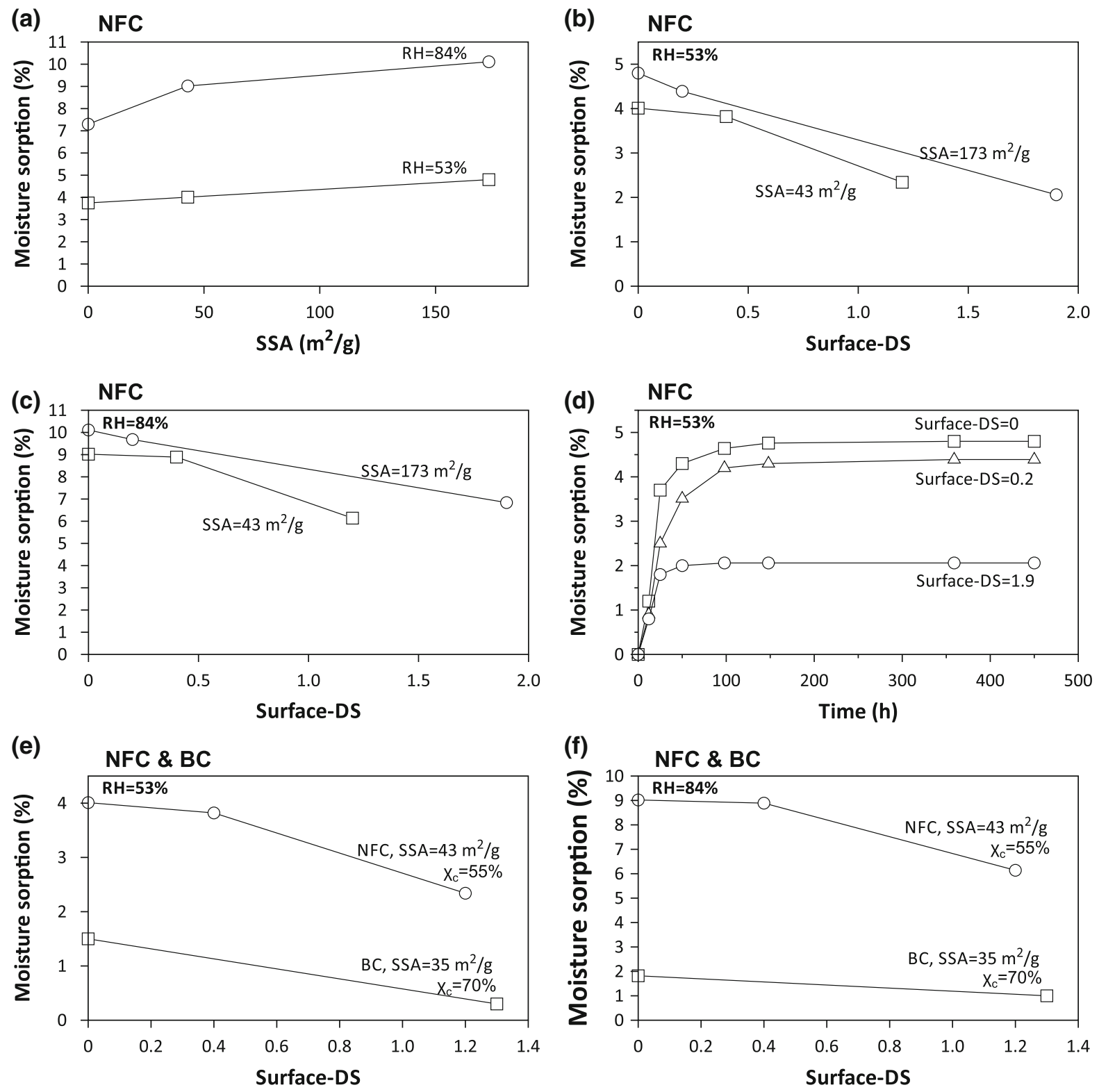

Fig. 7 Moisture sorption of a control NFC samples at RH $=53$ and $84 \%$; b, c control and acetylated CPD- and FD-dried NFC samples at $\mathrm{RH}=53$ and $84 \%$, respectively; d control and

is of practical interest and in support of hydration of nanofibril surfaces and disordered cellulose regions as the main mechanism for moisture sorption.

Demonstration 2 In order to study the potential of acetylated nanofibrils as reinforcing elements in composite materials, two different types of resinbased composites were prepared by resin

acetylated CPD-dried NFC samples over time at $\mathrm{RH}=53 \%$; and $\mathbf{e}$ and $\mathbf{f}$ control and acetylated FD-dried NFC and BC samples at $\mathrm{RH}=53$ and $84 \%$, respectively

impregnation of NFCcpd-Ref and NFCcpd-Ac2 nanopapers (Supporting information, Section S3). Biocomposites were made based on an acrylic resin matrix (Bisphenol A ethoxylate diacrylate) and an epoxy resin matrix (2,2-Bis(4-glycidyloxyphenyl)propane). These two composites contained around $20 \mathrm{wt} \%$ of cellulose, and were subjected to $\mathrm{RH}=84 \%$ and 


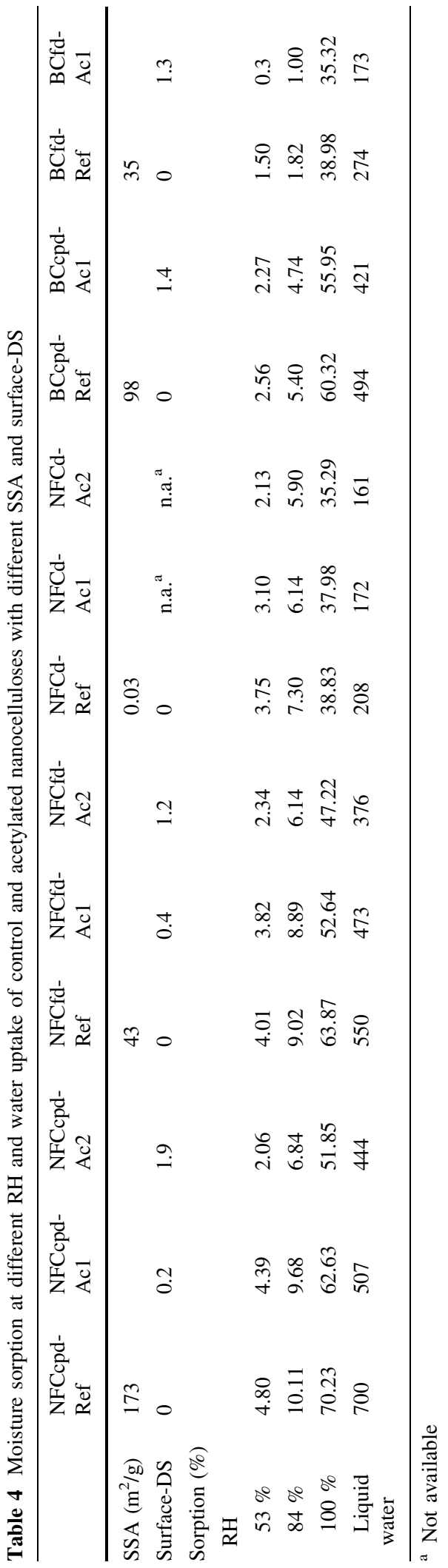

ambient temperature in order to determine the moisture content at steady state.

Biocomposites with unmodified NFC adsorbed more moisture than pure resins, due to the hydrophilic character of NFC surfaces and disordered regions (Fig. 10) (Ifuku et al. 2007; Zhang et al. 2011). However, the moisture content is much lower than for typical plant fiber biocomposites (Gaceva et al. 2007; Nguong et al. 2013), pointing to the advantage of nanocomposites based on cellulose of fairly high purity. Biocomposites based on acetylated NFC showed a significant decrease in moisture sorption, around $25 \%$, compared to the original composite (Fig. 10). For the acrylic resin, the moisture content of the acetylated NFC nanocomposite was almost as low as for the neat resin (Fig. 10a). It is possible that favorable interfacial acrylic-NFC interaction at molecular scale contributes to this result.

\section{Conclusions}

The moisture sorption in cellulose is addressed in a study of topochemical acetylation of porous cellulose nanofiber structures (nanopaper). The hypothesis that surface hydration of cellulose nanofibers dominates moisture sorption is supported by the data. At room temperature and $53 \% \mathrm{RH}$, the sorption is only $2.6 \%$ for porous BC nanopaper with a SSA of $100 \mathrm{~m}^{2} / \mathrm{g}$. Acetylation reduces this even further and if the $\mathrm{BC}$ structure is dried to $\mathrm{SSA}=35 \mathrm{~m}^{2} / \mathrm{g}$, the acetylated BC nanopaper sorbs only $0.3 \%$ moisture. Woodbased NFC nanofibers have higher SSA and a more disordered structure, but acetylated nanopaper still sorb as little as 2.0-2.3\% moisture at $53 \%$ RH. As the specific surface area, SSA, of acetylated NFC nanopaper is reduced by hot-pressing or resin impregnation, steady-state moisture content becomes so low that no moisture-induced swelling or mechanical property reduction will occur.

The acetylation treatment was carried out for NFC and BC nanopaper structures with different SSA. The modification was confirmed to be topochemical, since the cellulose I structure was preserved. The success of the reaction in terms of bulk-DS (from NMR) depended strongly on SSA. The cellulose hydroxyl groups need to be accessible, i.e., at nanofibril surfaces, for acetylation to occur. This explains erroneous claims that cellulose cannot be acetylated, since the 

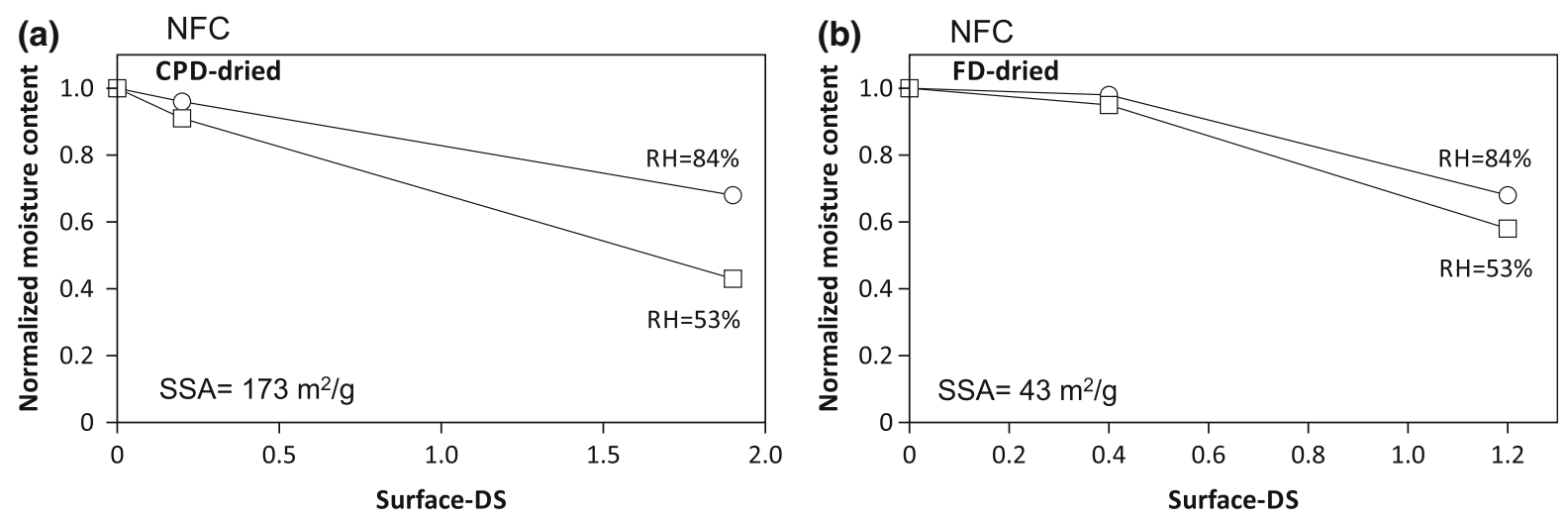

Fig. 8 Normalized moisture content (against the moisture content in the precursor samples) in the acetylated a CPD-dried and $\mathbf{b}$ FDdried NFC samples at $\mathrm{RH}=53$ and $84 \%$

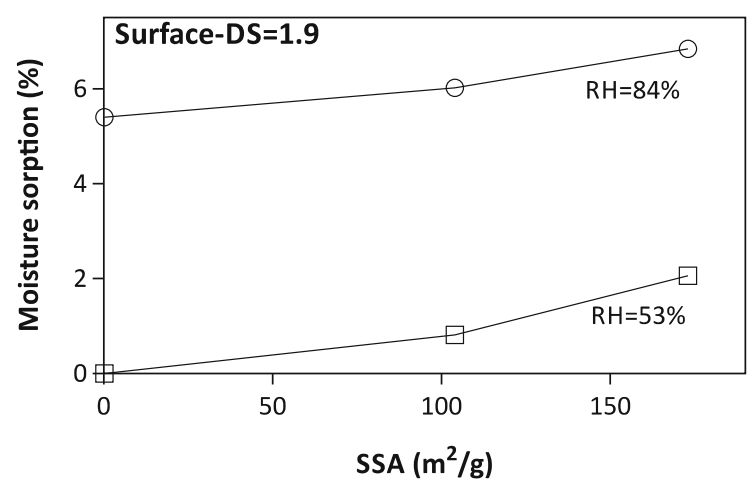

Fig. 9 Moisture sorption at RH $=53$ and $84 \%$ for CPD-dried NFC sample with the highest surface-DS after hot-press posttreatment in dry $\left(\mathrm{SSA}=104.2 \mathrm{~m}^{2} / \mathrm{g}\right)$ and wet conditions $\left(\mathrm{SSA}=0.2 \mathrm{~m}^{2} / \mathrm{g}\right)$

statement in a limited sense is true for low SSA specimens. Furthermore, for topochemical acetylation, the bulk-DS does not correlate with the amount of

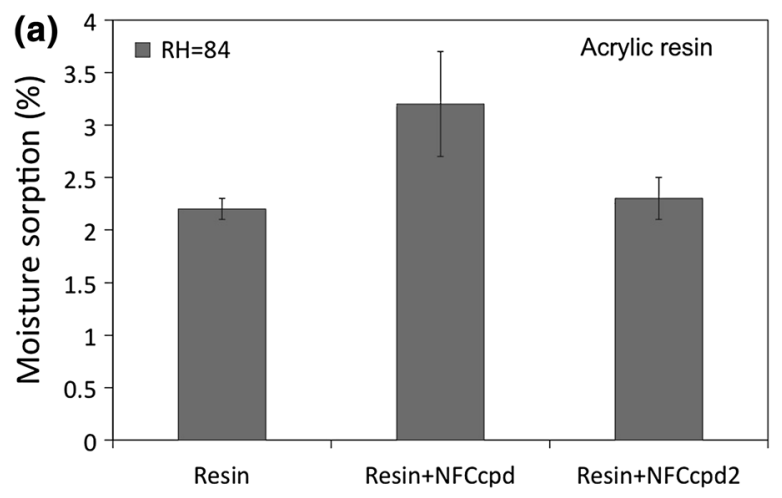

sorbed moisture. In the present study, surface-DS has therefore been estimated by normalization of bulk-DS with respect to data for accessible surface area.

The potential for NFC in new materials is substantial and for some cases, moisture sorption can be eliminated through topochemical modification combined with low SSA. As an example, hot-pressing of acetylated NFC nanopaper resulted in $0 \%$ moisture sorption at $53 \% \mathrm{RH}$.

Finally, BC nanofibers are $100 \%$ pure cellulose (no hemicellulose), show higher crystallinity, more consistent structure and have larger lateral fibril dimension than wood-based NFC, and a lower amount of accessible $\mathrm{OH}$-groups for surface hydration. BC-based samples therefore showed lower moisture content than NFC. The well-defined structural features makes BC well suited as a model system for basic studies of topochemical modification and moisture sorption effects.

Fig. 10 Moisture sorption at $\mathrm{RH}=84 \%$ of the $\mathbf{a}$ cellulose/acrylic resin and $\mathbf{b}$ cellulose/epoxy resin nanocomposites 
Acknowledgments This study was financially supported by CarboMat funded by The Swedish Research Council Formas and Wallenberg Wood Science Center (WWSC). Nordic Pulp and Paper industry (Sweden) is acknowledged for the kind donation of the wood pulp fibers, Núria B. Robles for providing the bacterial cellulose pellicles and Sylvain Galland for carrying out the BET measurements.

Open Access This article is distributed under the terms of the Creative Commons Attribution License which permits any use, distribution, and reproduction in any medium, provided the original author(s) and the source are credited.

\section{References}

Abdelmouleh M, Boufi S, Belgacem MN, Dufresne A, Gandini A (2005) Modification of cellulose fibers with functionalized silanes: effect of the fiber treatment on the mechanical performances of cellulose-thermoset composites. J Appl Polym Sci 98:974-984

Adamson AW, Gast AP (1997) Physical chemistry of surfaces, 6th edn. Wiley, Canada

Baggerund E, Stenström S, Lindström T (2003) Measurement of volume fractions of solid, liquid and gas in kraft and CTMP paper at varying moisture content. In: Proceedings of the international paper physics conference, TAPPI Press, Atlanta, pp 157-163

Belgacem MN, Gandini A (2005) The surfasse modification of cellulose fibres for use as reinforcing elements in composite materials. Compos Interface 12:41-75

Belgacem MN, Gandini A (2008) Monomers, polymers and composites from renewable resources. Elsevier, Oxford

Bellamy LJ (1975) The infrared spectra of complex molecules, 3rd edn. Chapman and Hall, London

Berglund LA, Peijs T (2010) Cellulose biocomposites-from bulk moldings to nanostructured systems. MRS Bull 35:201-207

Bochek AM, Kalyuzhnaya LM (2002) Interaction of water with celulose and celulose acetates as influenced by the hydrogen bond system and hydrophilic-hydrophobic balance of the macromolecules. Rus J Appl Chem 75:989-993

Boissard CIR, Bourban P-E, Tingaut P, Zimmermann T, Månson J-AE (2011) Water of functionalized microfibrillated cellulose as foaming agent for the elaboration of poly(lactic acid) biocomposites. J Reinf Plast Comp 30:709-719

Brunauer S, Emmett PH, Teller E (1938) Adsorption of gases in multimolecular layers. J Am Chem Soc 60:309-319

Chuniall V, Bush T, Larsson PT, Iversen T, Kindness A (2010) Controlling celulose fibril aggregation of Eucalyptus dissolving pulp samples. Holzforschung 64:693-698

Ciolacu D, Ciolacu F, Popa VI (2011) Amorphous celulose structure and characterization. Cell Chem Technol 45:13-21

Froix MF, Nelson R (1975) Interaction of water with cellulose from nuclear magnetic resonance relaxation times. Macromolecules 8:726-730
Gaceva G, B- Avella M, Malinconico M, Buzarovska A, Grozdanov A, Gentile G, Errico ME (2007) Natural fiber ecocomposites. Polym Comp 28:98-107

Gehlen MH (2010) Kinetics of autocatalytic acid hydrolysis of celulose with crystalline and amorphous fractions. Cellulose 17:245-252

Henriksson M, Henriksson G, Berglund LA, Lindstrom T (2007) An environmentally friendly method for enzyme-assisted preparation of microfibrillated cellulose (MFC) nanofibres. Eur Polym J 43:3434-3441

Hermans PH (1946) Contribution to the physics of celulose fibres. Elsevier, Amsterdam, p 57

Hestrin S, Schramm M (1954) Synthesis of cellulose by Acetobacter xylinum. 2. Preparation of freeze-dried cells capable of polymerizing glucose to cellulose. Biochem $\mathrm{J}$ 58:345-352

Howsmon JA (1949) Water sorption and the polyphase structure of cellulose fibers. Textile Res J 19:152-162

Hubbe MA, Rojas OJ, Lucia LA, Sain M (2008) Cellulosic nanocomposites: a review. BioResources 3:929-980

Ifuku S, Nogi M, Abe K, Handa K, Nakatsubo F, Yano H (2007) Surface modification of bacterial cellulose nanofibers for property enhancement of optically transparent composites: dependence on acetyl-group DS. Biomacromolecules 8:1973-1978

Kim D-Y, Nishiyama Y, Kuga S (2002) Surface acetylation of bacterial cellulose. Cellulose 9:361-367

Klemm D, Philipp B, Heinze T, Heinze U, Wagenknecht W (1998) Comprehensive cellulose chemistry: functionalization of cellulose. Wiley-VCH, Weinheim

Klemm D, Kramer F, Moritz S, Lindström T, Ankerfors M, Gray D, Dorris A (2011) Nanocelluloses: a new Family of nature-based materials. Angew Chem Int Ed 50:2-31

Larsson PT, Wickholm K, Iversen T (1997) A CP/MAS ${ }^{13} \mathrm{C}$ NMR investigation of molecular ordering in celluloses. Carbohyd Res 302:19-25

Mihrayan A, Llagostera AP, Karmhag R, Strømme M, Ek R (2004) Moisture sorption by cellulose powders of varying crystallinity. Int J Pharm 269:433-442

Morton WE, Hearle JWS (1997) Physical properties of textile fibres. The Textile Institute, UK

Newman RH (2004) Carbon-13 NMR evidence for cocrystallization of cellulose as a mechanism for hornification of bleached kraft pulp. Cellulose 11:45-52

Nguong CW, Lee SNB, Sujan D (2013) A review on natural fibre reinforced polymer composites. Int J Chem Mater Sci Eng 7:33-40

Niklas KJ (1992) Plant biomechanics: an engineering approach to plant form and function. The University of Chicago Press, Chicago

Okubayashi S, Griesser UJ, Bechtold T (2004) A kinetic study of moisture sorption and desorption on lyocell fibers. Carbohyd Polym 58:293-299

Pei A, Butchosa N, Berglund LA, Zhou Q (2013) Surface quaternized cellulose nanofibrils with high water absorbency and adsorption capacity of anionic dyes. Soft Matter 9:2047-2055

Peirce FT (1929) A two-phase theory of the adsorption of water by cotton cellulose. J Text Ins 20:133-150 
Peydecastaing J, Vaca-Garcia C, Borredon E (2011) Interaction with water of mixed acetic-fatty cellulose esters. Cellulose 18:1023-1031

Philipp B (1952) Kinetics and mechanisms of vapor sorption and swelling of cellulose. Ph.D. Thesis, TU Dresden

Rampinelli G, Landro LD, Fujii T (2010) Characterization of biomaterials based on microfibrillated cellulose with different modifications. J Reinf Plas Comp 29:1803-1973

Rowell RM, Rowell JS (1989) Cellulose and wood-chemistry and technology. In: Proceedings of the 10th celulose conference, John Wiley \& Sons, Inc., New York, pp 343-355

Sakurada I, Nukushina Y, Ito T (1962) Experimental determination of the elastic modulus of crystalline regions in oriented polymers. J Polym Sci 57:651-660

Salajkova M, Berglund LA, Zhou Q (2012) Hydrophobic cellulose nanocrystals modified with quaternary ammonium salts. J Mater Chem 22:19798-19805

Sassi J-F, Chanzy H (1995) Ultrastructural aspects of the acetylation of cellulose. Cellulose 2:111-127

Sehaqui H, Zhou Q, Ikkala O, Berglund LA (2011) Strong and tough cellulose nanopaper with high specific surface area and portosity. Biomacromolecules 12:3638-3644

Siqueira G, Bras J, Dufresne A (2010) Cellulosic bionanocomposites: a review of preparation, properties and applications. Polymers 2:728-765
Speakman JBT (1944) An analysis of the water adsorption isotherm of wool. Trans Faraday Soc 40:6-10

Stone JE, Scallan AM (1968) A structural model for the cell wall of water-swollen wood pulp fibres based on their accessibility to macromolecules. Cellulose Chem Technol 2:343-358

Sun CC (2008) Mechanisms of moisture induced variations in true density and compaction properties of microcrystalline cellulose. Int J Pharm 346:93-101

Tingaut P, Zimmermann T, Lopez-Suevos F (2010) Synthesis and characterization of bionanocomposites with tunable properties from poly(lactic acid) and acetylated microfibrillated cellulose. Biomacromolecules 11:454-464

Tomé LC, Pinto RJB, Trovatti E, Freire CSR, Silvestre AJD, Pascoal Neto C, Gandini A (2011) Transparent bionanocomposites with improved properties prepared from acetylated bacterial cellulose and poly(lactic acid) through a simple approach. Green Chem 13:419-427

Wada M, Sugiyama J, Okano T (1993) Native celluloses on the basis of two crystalline phase (I $\alpha / I \beta)$ system. J Appl Polym Sci 49:1491-1496

Wada M, Okano T, Sugiyama J (1997) Synchrotron-radiated $\mathrm{X}$-ray and neutron diffraction study of native cellulose. Cellulose 4:221-232

Zhang C, Wang L, Zhao J, Zhu P (2011) Effect of drying methods on structure and mechanical properties of bacterial cellulose films. Adv Mater Res 239-242:2667-2670 